\title{
Inhibitory priming in auditory word recognition: Is it really the product of response biases?
}

Sophie Dufour, Ulrich H. Frauenfelder and Ronald Peereman

\section{(2) OpenEdition}

1 Journals

\section{Electronic version}

URL: http://journals.openedition.org/cpl/2622

DOI: $10.4000 /$ cpl.2622

ISSN: $1379-6100$

\section{Publisher}

Centre PsyCLÉ

\section{Electronic reference}

Sophie Dufour, Ulrich H. Frauenfelder and Ronald Peereman, « Inhibitory priming in auditory word recognition: Is it really the product of response biases? », Current psychology letters [Online], 22, Vol. 2 2007 | 2007, Online since 12 September 2007, connection on 08 September 2020. URL : http:// journals.openedition.org/cpl/2622 ; DOI : https://doi.org/10.4000/cpl.2622

This text was automatically generated on 8 September 2020

(C) All rights reserved 


\title{
Inhibitory priming in auditory word recognition: Is it really the product of response biases?
}

\author{
Sophie Dufour, Ulrich H. Frauenfelder and Ronald Peereman
}

\section{Introduction}

Studies on auditory word recognition converge in showing that the processing of a target word is slowed down by the prior presentation of a prime overlapping in its first phonemes (Dufour \& Peereman, 2003a, 2003b; Hamburger \& Slowiaczek, 1996, 1999; Goldinger, Luce, Pisoni, \& Marcario, 1992; Monsell \& Hirsh, 1998; Radeau, Morais \& Segui, 1995; Slowiaczek \& Hamburger, 1992). However the cause of the inhibitory priming effect is the subject of controversy. Some have interpreted it as resulting from automatic competition between candidate words (Dufour \& Peereman, 2003a, 2003b; Hamburger \& Slowiaczek, 1996, 1999; Monsell \& Hirsh, 1998; Radeau et al., 1995; Slowiaczek \& Hamburger, 1992). For others, the inhibitory priming effect comes from response biases and thus cannot inform us about cognitive processes that occur automatically during auditory word recognition (Goldinger, 1999; Pitt \& Shoaf, 2002). In the present study, we have tried to test these alternative accounts.

An inhibitory priming effect was first reported by Slowiaczek and Hamburger (1992). Using monosyllabic words and shadowing latencies, these authors found an inhibitory priming effect with prime-target pairs overlapping in the first three phonemes (e.g., grief-green). In contrast, when the primes shared one (e.g., goals-green) or two (e.g., grope-green) phonemes with the targets, a facilitatory rather than an inhibitory priming effect was observed. Subsequently, Hamburger and Slowiaczek (1996) examined the phonological priming effect under conditions that either promote strategic processing (with $75 \%$ of related prime-target pairs and $500 \mathrm{~ms}$ ISI) or discourage it (with $21 \%$ of related trials and $50 \mathrm{~ms}$ ISI). Their earlier data were replicated with a high proportion of related trials (75\%) and a long ISI (500 ms). However, the facilitation effect vanished with a low proportion of related trials (21\%) and a short ISI ( $50 \mathrm{~ms}$ ), while the magnitude of the inhibition effect increased. Because the facilitation priming effect was larger when the proportion of related trials and the 
ISI increased, Hamburger and Slowiaczek concluded that this effect was strategically induced. With a high proportion of related trials, participants would notice that the targets are likely to begin with the same segments as the primes, and they anticipate the first phonemes of the targets, thus showing faster responses on targets preceded by related primes. In contrast, because the inhibition effect is stronger when strategic biases are minimized, Hamburger and slowiaczek assumed that it results from automatic processes involving competition between the lexical representations of the primes and targets ${ }^{1}$.

Two more recent studies have, however, favored an account of the inhibitory priming effect in terms of strategic processes (Goldinger, 1999; Pitt \& Shoaf, 2002). In a replication of Hamburger and Slowiaczek's (1996) study, Goldinger (1999) observed that RTs on target words preceded by unrelated primes became slower as the experiment progressed. This RT increase on the control trials was taken as evidence that participants develop strategic processes to maximize performance on the related trials (Posner \& Snyder, 1975; see also Goldinger et al., 1992). Although the RT cost in the control condition was larger with a high proportion of related trials (75\%) and a long ISI $(500 \mathrm{~ms})$, it was also observed with a low proportion of related trials $(21 \%)$ and a short ISI $(50 \mathrm{~ms})$. In the light of these results, Goldinger claimed that the inhibitory priming effect does not provide an accurate picture of lexical competition, because it co-occurs with evidence for response biases.

Whereas Goldinger focused only on the RT in the control condition, Pitt and Shoaf (2002) recently collected data on both related and unrelated prime-target pairs at different points during the experiment. They reasoned that if the inhibitory priming effect is evidence for lexical competition, it should be of similar magnitude at the beginning and the end of the experiment. As in Slowiaczek and Hamburger (1992) and Hamburger and Slowiaczek (1996), primes and targets shared zero (drive-state), one (swim-state), two (star-state) or three (steak-state) phonemes ${ }^{2}$, and the participants had to perform a shadowing task. In line with the study of Hamburger and Slowiaczek (1996), the ISI and the proportion of related prime-target pairs were manipulated. Overall, the results of Slowiaczek and Hamburger (1992) and Hamburger and Slowiaczek (1996) were closely replicated. The facilitation effect observed with a oneor two- phoneme overlap under condition including a high proportion of related trials (70 - 80\%) and a long ISI $(500 \mathrm{~ms})$ vanished when the proportion of related trials decreased $(10 \%)$ and the ISI shortened $(50 \mathrm{~ms})$. In contrast, prime-target pairs having a three-phoneme overlap produced a reliable inhibition effect only with a low proportion of related trials (10\%) and a short ISI (50 ms). Critically, however, a close examination of the data revealed that the size of the inhibitory priming effect decreased between the beginning and the end of the experiment. A strong inhibitory priming effect systematically occurred at the onset of the experiment, but no inhibition was found at the end of the experiment. To account for these data, Pitt and Shoaf (2002) suggest that inhibitory priming effects are due to participants' surprise that arises when they encounter the first related trial. Moreover, they suggest that priming effects are altered by strategic anticipations that participants develop in order to maximize fast responses on related trials, once the phoneme overlap between the primes and the targets has been noticed. Such an account was motivated by the observation that RTs on control trials increased and those on related trials decreased over the course of the experiment, a reliable indicator that response strategies were at work (Posner \& Snyder, 1975). 
A reappraisal of the response bias account

Although Pitt and Shoaf offer a reasonable explanation for the pattern of responses that they observed, a surprise account for the inhibitory priming effect is difficult to reconcile with experimental findings available in the literature. First, Dufour \& Peereman (2003a, 2003b) recently reported a series of priming experiments in which reliable inhibitory effects were observed despite the fact that related prime-target pairs were included in the training session. In these conditions, any surprise effect - if it occurred - should appear during the training session not during the testing session, since the participants should already have been familiarized with the prime-target overlap when the testing session began. Second, it has been found that the strength of the inhibitory priming effect varies as a function of the lexicality of the primes (Slowiaczek \& Hamburger, 1992), the relative frequency of the primes and the targets (Radeau et al., 1995) and the neighborhood density of the target words (Dufour and Peereman, 2003a). There is no reason to believe that the size of a surprise effect should vary as a function of these lexical factors. Finally, Dufour and Peereman (2003a) conducted additional analyses as a function of the presentation order to examine how the inhibitory effect developed over the course of the experiment. In contrast to Pitt and Shoaf, they observed that the inhibitory priming effect was still present at the end of the experiment and was of similar magnitude across the testing session. Such an observation has strong implications because it suggests that the observed inhibition was neither caused by a surprise on the first related trials nor eliminated by response biases that participants might have developed to maximize response speed on related trials.

Given the contradictions in the results, further examination of response biases is required. In particular, we deemed it useful to see how the inhibitory priming effect develops during the course of the experiment using an experimental design closer to the one found in usual priming experiments. Indeed, Pitt and Shoaf collected their data using a variant of the phonological priming design in which the first related primetarget pair occurred only after a sequence of 35 unrelated prime-target pairs. However, in other phonological priming studies (see Dufour \& Peereman, 2003a, 2003b), the structure of the items making up the training session was similar to that in the test session and thus includes related prime-target pairs. In addition, an examination of a priming experiment of Dufour and Peereman (2003a) in which trials were randomly presented, indicated that the first of the $25 \%$ related prime-target pairs of the testing session occurred early, between positions 1 and 13. Also for more than half of the participants (27 out of 41), the first related trials of the testing session occurred very early in positions 1 to 4 . Hence, it seems important, as Pitt and Shoaf state (p 1128), to determine what impact the late position of the first related prime-target pair had on participants' performance. This is precisely the question that we examined below.

As in Pitt and Shoaf (2002), we compared the size of the priming effect to the same items occurring at the beginning and at the end of the testing session. To prevent a surprise that could cause or amplify the expected inhibitory priming effect, participants were led to infer the existence of phonological overlap before the beginning of the testing session by including related prime-target pairs in the practice trials. Because Dufour and Peereman (2003a) reported an inhibitory priming effect for target words occurring in low-density neighborhoods but not in high-density neighborhoods, targets of the former type were tested. The materials were from Dufour and Peereman (2003a) in which related prime-target pairs overlapped by two 
phonemes out of three (e.g. bouche /buf/ - boule /bul/). Although Pitt and Shoaf (2002) used primes and targets sharing three phonemes, this change in the amount of overlap is not particularly troublesome. Indeed, Dufour and Peereman (2003b) showed that inhibitory priming effects emerge both with a three- and a two- phoneme overlap provided that the primes diverge from the targets only on the last phoneme (e.g. bouche /buf/ - boule /bul/ for a two-phoneme overlap and brise /bRiz/ - brique /bRik/ for a three-phoneme overlap). As in Pitt and Shoaf, participants had to perform a shadowing task. To limit strategic effects that could mask the inhibitory priming effect, we used a low proportion of related trials (25\%) and a short ISI (50 ms; see Hamburger \& Slowiaczek, 1996, 1999).

MethodParticipants

One hundred forty students from the University of Bourgogne, 5 per stimulus lists, participated in the experiment for course credit. All were native speakers of French and reported no hearing or speech disorders.

Materials

Twenty-eight monosyllabic target words, three phonemes in length, from the study of Dufour and Peereman (2003a) were used. They had an average of 3.18 phonological neighbors (range: 1-5). Competitors were defined sequentially in terms of candidates that are aligned with the onset of the target word (Marslen-Wilson, 1990). Because some recent data suggest that words are quickly deactivated once they no longer match the incoming signal (Frauenfelder, Scholten, \& Content, 2001), only the words that diverged from the target word in their final phoneme were counted. Each of the 28 target words had two corresponding monosyllabic primes of three phonemes in length. One shared the first two phonemes with the targets (e.g. MOULE /mul/ - MOUCHE / $\mathrm{mu} / /$ ), and the other, the control, had no phonemes in common with the targets (e.g. BULLE /byl/ - MOUCHE / $\mathrm{mu} /$ /). Because it had previously been observed that primes sharing initial phonemes with the targets produce more inhibition in the shadowing task when they are of lower frequency than the targets (Radeau et al., 1995), the less frequent word in each of the prime-target pairs was always used as the prime. The targets had a mean frequency of 125 occurrences per million (Vocolex, Dufour, Peereman, Pallier \& Radeau, 2002). The mean frequencies of related and control primes were 22 and 15 respectively $(F(1,54)=1.34 ; p>.20)$.

Design

Each target was paired with two different primes (related and control). Two experimental lists were created so that no subject was presented with the same target twice. Each list included the 28 target words. Fourteen were preceded by a related prime, and the 14 remaining ones were preceded by a control prime. The lists were counterbalanced such that each target was preceded by the two types of prime. To achieve a proportion of related prime-target pairs of $25 \%, 28$ fillers trials without any relation between the primes and the targets were included in each list.

To have a list structure as close as possible to that usually found in priming studies, the first related trials of the testing session occurred early, after three unrelated trials with no overlap between the primes and targets. Within each list, the first four (beginning of the testing session) and the last two trials (end of the testing session) were fixed. Trials 1 and 2 were unrelated filler trials. Trials 3 and 4 defined the early probe position and Trials 55 and 56 defined the late probe position. The first trial of each of the probe positions (Trials 3 and 55) was a control trial. The second trial of each of the probe 
positions (Trials 4 and 56) was therefore a related trial.The remaining trials (12 control trials, 12 related trials and 26 filler trials) occurred in a randomly presented order, as is usually the case in priming studies. So that each target appears in each of the probe positions, the 28 target words were rotated through the four trials (Trials 3, 4, 55 and 56) across stimulus lists, thus leading to the creation of 28 sub-lists. The participants were tested on only one experimental list and they began the experiment with a block of 32 practice trials in which 8 prime-target pairs were phonologically related, making thus unlikely that participants were surprised when they encountered related trials in the testing session ${ }^{3}$. The experimental list structure is depicted in Table 1.

Table 1. Illustration of the experimental list structure

\begin{tabular}{|c|c|c|}
\hline Trial no. & Examples & Trial type \\
\hline 1 & vache - lampe & filler \\
\hline 2 & pince - monde & filler \\
\hline & Early probe position & \\
\hline 3 & puce - vol & control \\
\hline 4 & sainte - singe & related \\
\hline & Randomly presented trials & \\
\hline 5 & bêche - faute & filler \\
\hline 6 & quiche - jour & control \\
\hline . & & \\
\hline . & & \\
\hline 53 & jauge-jaune & related \\
\hline 54 & coude-père & filler \\
\hline & Late probe position & \\
\hline 55 & gomme-songe & control \\
\hline 56 & ronce-ronde & related \\
\hline
\end{tabular}


Procedure

The stimuli were recorded by a female native speaker of French on a digital audio tape recorder. The items were digitized at a sampling rate of $44 \mathrm{kHz}$ with 16-bit analog to digital recording. The participants were tested individually in a quiet room. The presentation of the items was controlled by a personal computer. RTs were collected via a voice key connected to the computer. The primes and the targets were presented over headphones at a comfortable sound level. An interval of $50 \mathrm{~ms}$ (ISI) separated the offset of the prime and the onset of the target. The participants were asked to repeat the target as quickly and accurately as possible.The subject's response and the onset of the prime of the following trial were separated by 2 seconds. The naming latencies were measured from the onset of the target to the triggering of the voice key. The experimenter noted whether the pronunciation was incorrect and whether the recorded latency was invalid, in case of triggering the voice key by extraneous sounds. A response was considered incorrect in the case ofhesitation or when at least one phoneme in the subject's production differed from the expected response.

Results and Discussion

Incorrect responses and voice key errors were discarded from the analyses. The error rates in participant's responses were extremely low and did not exceed $1 \%$ in any of the priming conditions. Therefore, we will not discuss them further. The global mean RTs for the entire experiment were $815 \mathrm{~ms}$ for the control primes and $833 \mathrm{~ms}$ for the related primes. Analyses of variance (ANOVA) including the factor prime typewas reliable both by subjects $(F 1(1,139)=35.59, \mathrm{MSE}=690, p<.001)$ and by items $(F 2(1$, $27)=12.20, \mathrm{MSE}=402 ; p<.01)$. Note that the size of our inhibitory priming effect (18 $\mathrm{ms}$ ) was quite similar in size that $(25 \mathrm{~ms}$ ) reported by Goldinger (1999) with the same proportion of related prime-target pairs (25\%) but was half the size of the 36 and $34 \mathrm{~ms}$ inhibition effects respectively reported by Hamburger and Slowaczek (1996) and Pitt and Shoaf (2002; Experiment 3) under a low proportion of related prime-target pairs (25\% in Hamburger and Slowiaczek and $10 \%$ in Pitt and Shoaf). The difference in the size of our inhibitory priming effect and that reported by Pitt and Shoaf (2002) most likely results from the extremely slow responses in the related condition (inhibitory effect of $85 \mathrm{~ms}$ ) found by the authors for the early probe position. The same reason can be invoked to account for the difference in the size of the effect between our experiment and that of Hamburger and Slowiaczek (1996). Indeed, a large slow-down (76 ms) on the first related trials was found by Pitt and Shoaf, in a re-analysis of the Hamburger and Slowiaczek experiment. Note that like in Pitt and Shoaf, in Hamburger and Slowiaczek's study there were no prime-target pairs with phonemic overlap; therefore the first related trials occurred over a wide range of trials, between positions 3 to 27 . Hence, of particular interest here is whether or not the size of the inhibitory priming effect changes between the beginning and the end of the testing session, when participants were assumed to know from the outset via the training session that the primes and the targets sometimes overlap in their first phonemes. Figure 1 shows the mean RTs as a function of prime type across the two probe positions (early, late). ANOVAs with prime type and probe position as variables showed no interaction ( $F 1$ (1, 139) $=0.34, \mathrm{MSE}=12647 ; F 2(1,27)=0.14, \mathrm{MSE}=5022)$. 


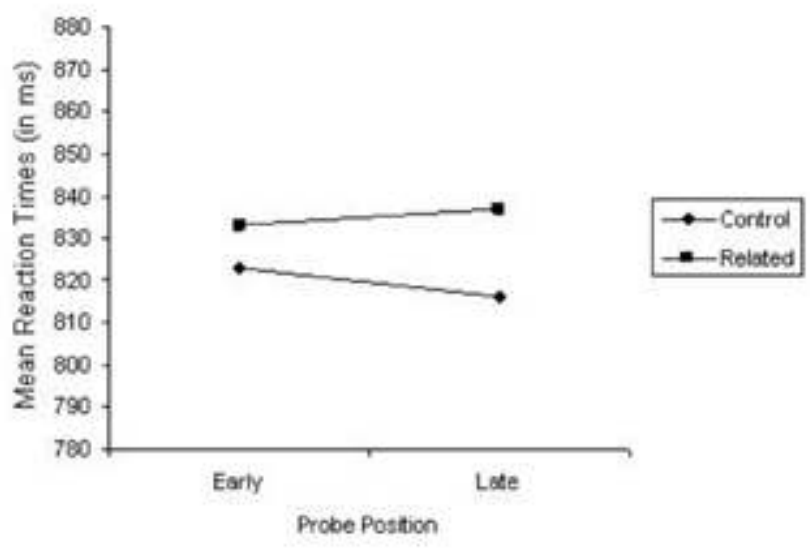

Figure 1. Mean Reaction Times (in ms) for related and control primes as a function of probe position.

To sum up, we found a reliable inhibitory priming effect even when the participants were assumed to know - via the training session - that the primes and targets sometimes overlapped in their first phonemes. Thus, it seems unlikely that the inhibitory priming effect observed here results from participant's surprise. Second, the probe position data indicated that the effect was of similar magnitude at the beginning and the end of the testing session. As can be seen, the RT cost on control trials found by Goldinger (1999) and Pitt and Shoaf (2002) was not replicated here, since the RTs on control trials were strikingly similar at the early $(823 \mathrm{~ms})$ and the late probe position $(816 \mathrm{~ms})$. Also, there was no change in the RTs for the related trials across the probe positions (833 and $837 \mathrm{~ms}$ for the early and late probe positions, respectively). These observations suggest that response strategies have had no impact in our experiment. One reason is that the participants did not have enough trials to implement an overlapguided response strategy. Indeed, the testing session in our experience included 56 trials in which only 14 were related: Thus the participants had few opportunities to develop and apply a response strategy which would permit them to deal more effectively with prime and target overlap. Compatible with such a claim, Pitt and Shoaf (2002) showed that the inhibitory priming effect, although non significant that was found in positions 90-91 disappeared and was reversed in the late probe position defined by trials 199 and 200. It thus remains possible that short experiments like ours are necessary to minimize response bias effects, by preventing strategic anticipations from developing sufficiently to have a significant impact on performance. Practice effects have been envisaged by Pitt and Shoaf to account for the fact that the inhibitory priming effects are stronger with a low than with a high proportion of related trials. Indeed, when the proportion of related trials is high and so when participants have additional practice, they are more likely to improve their performance on the related trials and to respond faster on these trials, masking thus the inhibitory priming effect.

What is the cause of our inhibitory priming effect? To answer this question, we examined how the magnitude of the effect correlates with neighborhood density. The logic is simple. If the present inhibitory priming effect results from automatic competition between the lexical representations of the primes and the targets, then lexical factors such as the neighborhood density of the target words should influence 
the size of the inhibitory priming effect. Figure 2 shows the relation between the size of the inhibitory priming effect and the neighborhood density of the target words. Globally, the resulting correlation was negative $(r=-.39, p<.05)$, showing that the size of the effect decreases as the neighborhood density of the target words increases ${ }^{4}$. Thus, a phonologically related prime acts as a stronger competitor of the target word when there is only one another competitor in the competition process than when there are five, thus causing a greater inhibitory priming effect in the former than in the latter case. According to Dufour and Peereman (2003a), the observation that the size of the inhibitory priming effect varies as a function of the neighborhood density of the target words can readily be accounted for by models like TRACE (McClelland \& Elman, 1986) that includes lateral inhibition mechanism. When there are few words in the competition process, the prime itself receives little inhibition from others competitors, and thus is more effective in inhibiting target word recognition. Although words were intentionally selected to occur in a sparse neighborhood, the negative correlation between the size of the inhibitory priming effect and the neighborhood density suggests that each additional competitor exerted its own influence in the competition process (see also, Frauenfelder \& Peters for simulations with the TRACE model). Hence, the observation that the neighborhood density of the target words influences the size of the inhibitory priming suggests that the present inhibitory priming effect reflects, at least in part, lexical processing.

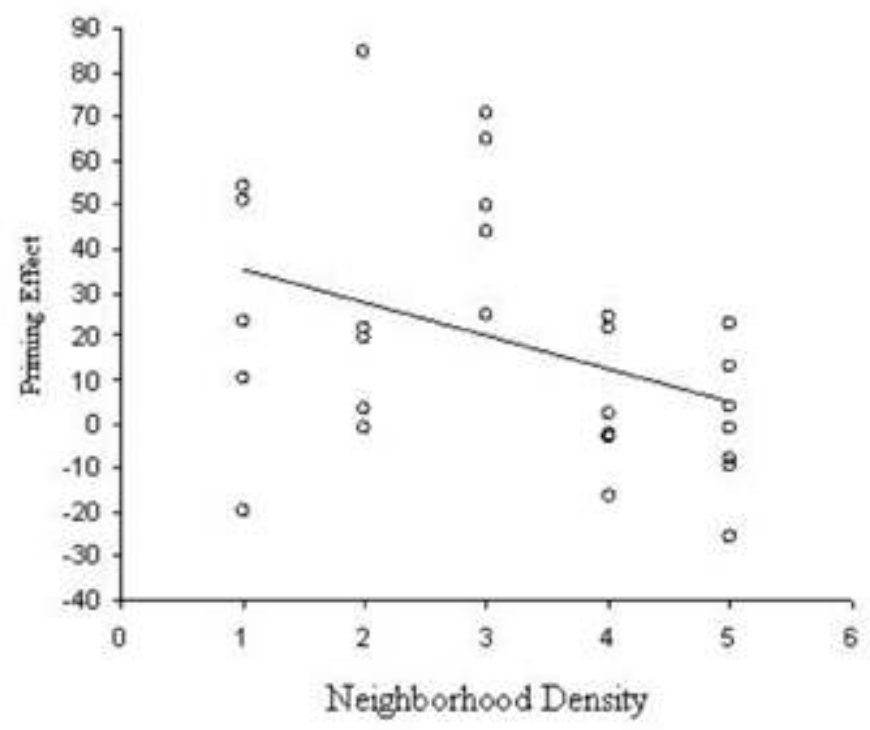

Figure 2. Catterplot of priming effects (in ms) as a function of neighborhood density. Conclusion

Listeners respond more slowly to target words when they follow primes with which they share the first phonemes. Pitt and Shoaf (2002) recently claimed that such inhibitory priming effect results from participants' surprise when they encounter the first related trials. This study addressed the surprise issue and sought to clarify the cause of the inhibitory priming effect when primes and targets overlap in their first phonemes.

As in Pitt and Shoaf (2002)'s study, the magnitude of the inhibitory priming effect was compared at the beginning and the end of the experiment. To prevent a surprise effect that could cause or amplify the inhibitory priming effect, participants were 
familiarized with the overlap before the testing session, by including related primetarget pairs in the practice trials. This latter methodological aspectconstituted the major difference between our experiment and that of Pitt and Shoaf (2002) in which the first related trials occurred late, only after a sequence of 35 unrelated prime-target pairs. The major result of this study is that inhibitory priming was observed when participants presumably knew - via the training session - that the primes and the targets sometimes overlapped in their first phonemes. Thus, in contrast to what was observed by Pitt and Shoaf, the present inhibitory priming has nothing to do with a surprise effect.

Our results indicate that the number of words that are pre-activated by the prime during the processing of the target word is an important factor in determining the size of the inhibitory priming effect (see also, Dufour \& Peereman, 2003a). The observation that the size of the inhibitory effect correlates with neighborhood density strongly suggests that an important part of the effect is lexical in nature, and reflects automatic lexical competition rather than purely strategic processing. In accordance with such a claim, other studies have shown that the inhibitory priming effect also varies as a function of the lexicality of the primes (Slowiaczek \& Hamburger, 1992) or the relative frequency of the primes and targets (Radeau et al., 1995). Hence, it seems that an explanation of the inhibitory priming effect in terms of an automatic competition between lexical candidates is appropriate. This does not mean however that response biases are absent in phonological priming experiments. Indeed, as we have seen, several studies have reported evidence for response biases (Goldinger et al., 1992; Goldinger, 1999; Hamburger \& Slowiaczek, 1996; Pitt and Shoaf, 2002). Nonetheless, both the study of Hamburger and Slowiaczek (1996) and that of Pitt \& Shoaf (2002) showed that the size of the inhibitory priming effect decreases as strategic processes build-up. Thus, it appears that response biases in phonological priming experiments can mask but under no circumstance cause the inhibitory priming effect. Although further research is required, our study indicates that experiments with few experimental trials could prevent strategic processing from developing fully and from having a significant impact on the inhibitory priming effect.

Acknowledgments

Many thanks to Mark Pitt and Louisa Slowiaczek who provided helpful comments on an earlier version of this manuscript.

\section{BIBLIOGRAPHY}

Dufour, S., Peereman, R., Pallier, C., \& Radeau, M. (2002). VoCoLex: A lexical database on phonological similarity between French words. L'Année Psychologique, 102, 725-746.

Dufour, S. \& Peereman, R. (2003a). Inhibitory priming effects in auditory word recognition: When the target's competitors conflict with the prime word. Cognition, 88, B33-B44. 
Dufour, S. \& Peereman, R. (2003b). Lexical Competition in phonological priming: Assessing the role of phonological match and mismatch lengths between primes and targets. Memory and Cognition, 31, 1271-1283.

Frauenfelder, U. H., Scholten, M., \& Content, A. (2001). Bottom-up inhibition in lexical selection: Phonological mismatch effects in spoken word recognition. Language and Cognitive Processes, 16, 583-607.

Frauenfelder, U. H., \& Peters, G. (1998). Simulating the time course of word recognition: an analysis of lexical competition in TRACE. InJ. Grainger \& A. Jacobs (Ed.), Symbolic/ connectionist approaches to human cognition (PP. 102-145). Hillsdale, NJ: Lawrence Erlbaum Associates.

Goldinger, S. D. (1999). Only the Shadower knows: Comment on Hamburger \& Slowiaczek (1996). Psychonomic Bulletin and Review, 6, 347-351.

Goldinger, S. D., Luce, P. A., Pisoni, D. B., \& Marcario, J.K. (1992). Form-based priming in spoken word recognition: The roles of competition and bias. Journal of Experimental Psychology: Learning, Memory \& Cognition, 18, 1211-1238.

Hamburger, M. B., \& Slowiaczek, L. M. (1996). Phonological priming reflects lexical competition. Psychonomic Bulletin \& Review, 3, 520-525.

Hamburger, M. B., \& Slowiaczek, L. M. (1999). On the role of bias in dissociated phonological priming effects: A reply to Goldinger (1999). Psychonomic Bulletin \& Review, 6, 352-355.

McClelland, J.L., \& Elman, J.L. (1986). The TRACE model of speech perception.

CognitivePsychology, 18, 1-86.

Marslen-Wilson, W.D. (1990). Activation, competition, and frequency in lexical access. In G. T. M. Altmann (Edit.), Cognitive models of speech processing: Psycholinguistic and computational perspectives (PP. 148 -172). Cambridge, MA: MIT Press.

Monsell, S., \& Hirsh, K.W. (1998). Competitor priming in spoken word recognition. Journal of Experimental Psychology: Learning, Memory \& Cognition, 24, 1495-1520.

Pitt, M.A. \& Shoaf, L. (2002). Revisiting bias effects in word-initial phonological priming. Journal of Experimental Psychology: Human Perception and Performance, 28, 1120-1130.

Posner, M. I., \& Snyder, C. (1975). Facilitation and inhibition in the processing of signals. In P. M. A. Rabbit \& S. Dornic (Eds.), Attention and performance $V$ (pp. 669-681). New York: Academic Press.

Radeau, M., Morais, J., \& Segui, J. (1995). Phonological priming between monosyllabic spoken words. Journal of Experimental Psychology: Human Perception and Performance, $21,1297-1311$.

Slowiaczek, L. M., \& Hamburger, M. B. (1992). Prelexical facilitation and lexical interference in auditory word recognition. Journal of Experimental Psychology: Learning, Memory and Cognition, 18, 1239-1250.

\section{NOTES}

1. Although the shadowing task involves a production component, it seems unlikely that the inhibitory priming effect found in this task reflects speech production processes such as inhibition at the level of preparing a motor program. Indeed, in such 
a case, one would expect that the effect occurs regardless of the lexicality of the prime. Nonetheless, Slowiaczek and Hamburger (1992) found no evidence for inhibitory priming effect when non-words were used as primes.

2. Only the effect caused by a three-phoneme overlap was examined at the beginning and the end of the experiment. Indeed, it was in this condition that Slowiaczek and Hamburger (1992) and Hamburger and Slowiaczek (1996) reported slower response times to related trials.

3. In the training session, the first related trials occurred early between positions 2 to 4 . Thus, our intention in this experiment was not to replicate the surprise effect found by Pitt and Shoaf (2002).

4. Note that the size of the effect did not correlate with target word duration. Hence, it is not the durational differences between words that are responsible for the correlation between the size of the inhibitory priming effect and the target word neighborhood density. Table 1: Illustration of the experimental list structure.

\section{ABSTRACTS}

Phonological priming studies have revealed slower responses to auditory target words when they are preceded by a prime that begins with the initial phonemes. However the interpretation of such an inhibitory priming effect has not been consensual. Whereas some authors have interpreted this effect as reflecting lexical processes, Pitt and Shoaf (2002) have argued that this effect comes from participants' surprise when they encounter the first related trials. To avoid such a response bias, we included related prime-target pairs in the training session and, like in Pitt and Shoaf's study, compared the magnitude of the inhibitory priming effect to the same items occurring at the beginning and at the end of the experiment. No change in the magnitude of the inhibitory priming effect was found over the course of the experiment. Moreover, an additional analysis showed that the inhibitory priming effect correlates with the neighborhood density of the target words. These findings suggest that the effect is lexical in nature and does not reflect purely strategic processes.

Les études en amorçage phonologique ont révélé des temps de réponse plus lents lorsque des mots cibles sont précédés d'une amorce partageant avec eux les premiers phonèmes. Cependant, l'interprétation de l'effet d'amorçage inhibiteur est source de controverses. Alors que certains auteurs ont interprété l'effet comme reflétant des processus lexicaux, Pitt et Shoaf (2002) ont émis l'hypothèse que l'effet résulterait d'une surprise des participants lorsqu'ils rencontrent le premier essai relié. Pour éviter un tel biais de réponse, nous avons inclus des amorces et des cibles reliées dans la session d'entraînement, et nous avons comparé comme l'ont fait Pitt et Shoaf, l'amplitude de l'effet sur le même item à différents points durant le décours temporel de l'expérience. Aucun changement dans la taille de l'effet entre le début et la fin de l'expérience n'a été observé. De plus, une analyse additionnelle a montré que la taille de l'effet corrèle avec la densité du voisinage phonologique. Cette observation indique que l'origine de l'effet est lexicale et qu'il n'est pas exclusivement le reflet de processus stratégiques. 
INDEX

Keywords: Phonological priming, Lexical activation, response biases

\section{AUTHORS}

SOPHIE DUFOUR

Laboratoire de Psycholinguistique Expérimentale, University of Geneva, $40 \mathrm{Bd}$ du Pont d'Arve CH 1205, Genève, Switzerland. Email: Sophie.Dufour@pse.unige.ch

ULRICH H. FRAUENFELDER

Laboratoire de Psycholinguistique Expérimentale, University of Geneva, Switzerland

RONALD PEEREMAN

University of Bourgogne \& CNRS, Dijon, France 